\title{
Performance Evaluation and Comparison of Dynamic Routing Protocols for Suitability and Reliability
}

\author{
Salah A. Alabady ${ }^{1 *}$, Sara Hazim² ${ }^{2}$ and Abdullah Amer ${ }^{3}$ \\ ${ }^{1}$ College of Engineering, Computer Engineering Department, \\ University of Mosul, Iraq \\ ${ }^{2}$ College of Engineering, Civil Engineering Department, \\ University of Mosul, Iraq \\ ${ }^{3}$ School of Electrical and Electronic Engineering, \\ Universiti Sains Malaysia / Malaysia \\ 1eng.salah@uomosul.edu.iq, ${ }^{2}$ engsarah1988@yahoo.com, \\ 3eng.abdullah86@gmail.com
}

\begin{abstract}
This paper presents the evaluation performance and suitability comparison between the dynamic routing protocols which they are, Enhanced Interior Gateway Routing (EIGRP), Open Shortest Path First (OSPF), and Routing Information Protocol (RIP). It shows which protocol is the best and fastest in building and maintenance in the routing table's update and selecting the best path, finding which routing protocol is the fastest convergence than other in case link path failure or a router is shutdown. Additional, also it shows how the numbers of routers are effecting on the performance of the network such as delay and converge. The simulation results show the best performance between them in large networks and under the hardest situations that it may face the routers when a big issue been happened such electricity fail or disaster like earthquake or flood. The results demonstrate that the OSPF is faster convergence and more reliability than RIP and EIGRP. The work is achieved by using Packet Tracer simulation program.
\end{abstract}

Keywords: Dynamic Routing Protocoles, RIP, OSPF, EIGRP, Network Performance

\section{Introduction}

Currently, Internet and communication networks have important influence on our lives by allow the people to communicate and collaborate. There are variety of ways to use network, including education, video conferencing, web applications, IP telephony, and more. Network devices included; switches, hubs, bridges, access points, antennas, and routers. The most important device in the network is a router that used to connect between two different networks [1].

The major accountability of a router is to deliver packets from source to destination without any lost in the packets [2]. To deliver packets, router uses routing protocols that defined by the set of algorithms and processes that are used to simplify the exchange routing information and routing table. The aim of routing protocols is finding the best path in the network to guarantee its connectivity. Each routing protocol has its own standards to evaluate a route quality by using metrics such as next hop count, bandwidth, and delay A router used routing table information to determine the best path to forward the packet $[3,4,5]$. A routing protocol selects the best path based on the value or metric it uses to determine the distance to destination network. As example, Routing information Protocol (RIP)

Received (December 19, 2017), Review Result (January 17, 2018), Accepted (June 20, 2018)

* Corresponding Author 
uses hop-count metric to select a best path which is not always best metric to use [6]. It is one of the distance vector routing protocols that is quite simple protocol. While the Open Shortest Path First (OSPF) uses a bandwidth of link as it's metric and provide the overcome many of the efficiency and the problem with RIP [5] [1]. Dynamic routing protocol can use to segment large networks where multiple paths are possible and static routing is not practical.

Distance vector and link-state routing protocols are the two categories of dynamic routing protocols. Distance vector routing protocols included; RIP and IGRP (Interior Gateway Routing Protocol). Link-state routing protocols included; OSPF and Intermediate System-to-Intermediate System (IS-IS) [7]. EIGRP (Enhanced IGRP) exhibits both distance-vector and link-state characteristics, and is considered a hybrid protocol. Link-state protocols are more complex than distance vector protocols, and running them adds to the router's overhead [8]. Readers should refer to $[9,10]$ for a more thorough description survey of various dynamic routing protocols consisting of RIP, EIGRP and OSPF primarily based on different metrics.

The goal of this paper is a comparison between the dynamic routing protocols in the big network and hardest situations is introduces. This research investigates which protocol is the best, fastest in building and maintenance in the routing table's update, selecting the best path, and which routing protocol is the fastest convergence than others is provided. The protocol performance investigate is down in the big network which contains 25 routers and under the hardest situations that it may face the routers when a big issue been happened such like a disaster like earthquake or flood or electricity fail.

The paper is organized as follows: Literature review is presented in Section II. Section III presents simulation results and discussion, and Section IV concludes the paper.

\section{Literature Review}

In this section, a related work is presented. The authors in [11] compared the performance of the IS-IS, RIP and EIGRP routing protocols in terms of end-to-end delay, throughput and convergence time. The authors proposed that which routing is suitable for IP networks by chosen three different applications FTP, e-mail, and video conferencing. OPNET simulation program was used to design and simulate the network. Simulations results demonstration that the combination of RIP and IS-IS protocols have better performance compared with EIGRP protocol in terms of end-to-end delay and throughput. Whereas, the network convergence of EIGRP protocol is better than RIP and IS-IS protocols.

In, [12] three network models are configured with OSPF, EIGRP and combination of EIGRP and OSPF protocols respectively. The evaluation performance protocols based on the quantitative metrics such as end-to-end delay, throughput, packet loss, convergence time, and jitter are presented. Simulation results demonstrated that the performance of combined EIGRP and OSPF routing protocols is better than OSPF and EIGRP individually. However, the overall performance of EIGRP is better than OSPF individually.

In [4] the authors used group of parameters to evaluation the performance of RIP, OSPF, and EIGRP protocols. These parameters are: end-to-end delay, traffic sent, and convergence duration. OPNET simulation tool is used to compare different routing protocols besides comparing different area division topologies and measuring different performance parameters. In network convergence parameter the EIGRP gave the best conversion duration and was the first to converge. Furthermore, it had the best response to node failure thus in conversion duration it is more reliable in real time applications. OSPF was the one with the most traffic sent and the last one to send routing traffic. EIGRP was 
the first one to send traffic, whereas RIP protocol had the least traffic, as it sends only the number of hops.

A comparison between OSPF, EIGRP, and RIP routing protocols is presented in [13]. Simulation results show the performance of EIGRP compared to RIP and OSPF is better in terms of network convergence activity, routing protocol traffic, and Ethernet delay. OSPF performs better in terms of http page response time and video conferencing packet end-to-end delay. RIP performs better in terms of voice packet delay. Performance comparison of two dynamic routing protocols: RIP and OSPF have evaluated using Network Simulator (NS2) in [14]. Simulation results demonstration that OSPF has a better performance than RIP in terms of average throughput and packet delay in different network sizes. The performance and compared of RIP \& EIGRP Protocols using GNS3 Software has analyzed. The author has concluded that the EIGRP protocol is better than RIP protocol [15]. The authors in [16] have analyzed three routing protocols, RIP, IS-IS and IGRP on the basis of Ftp Download Response time and Ftp Upload Response time scenario. A comparison between difference routing protocols (RIPv1, RIPv2, OSPF and EIGRP) has been done and discussed in [17] to determine the protocol needed for each network topology. In [18] a performance of RIPv2 protocol is optimized using enhanced routing parameter like routing update, convergence time, invalid timer, and hold timer.

The authors in [19] studied and analyzed RIPv2, EIGRP and OSPFv2 protocols based on the bandwidth used during convergence, using real-time networking devices. In addition, the authors have been testing and analysis the unequal-cost, load balancing capability for those three protocols in order to address the issue of choosing the optimal routing protocol based on the network requirements. The results show that the same protocol may not be the best for all kinds of networks. It all depends on the network environment and business needs. In [20] the types of dynamic routing protocols, aim of dynamic routing protocols, and analyses of dynamic routing protocols on different network topologies were elucidated. The authors analyses the performances operations of different routing protocols in a variety of network topologies (ring, star, and mesh). The performance comparison of RIP, OSFP and EIGRP routing protocol and suggesting the best routing protocol for the given topology was introduce in [21]. The results are determined that choice of routing protocol depends on different critical parameters like convergence time, scalability, memory and CPU requirements, security and bandwidth requirement.

The author in [22] has analyzed and simulated a proposed wired Local Area Network using different routing protocols using CISCO packet tracer simulator. A comparing between OSPF and RIP protocols show that, OSPF prevails RIP in terms of throughput and delay in different size of network. S. Sirika and S. Mahajine [23] study and compare the performance of RIP, EIGRP, and OSPF to show which protocol performs better in real time application by using Cisco packet tracer and OPNET simulators. The results show the RIPv2 protocol is suitable for small network and EIGRP is best for fast convergence.

A. Bahnasse and N. E. Kamoun [24] have studied the suitable configurations of EIGRP, OSPF and BGP routing protocols for a scalable Dynamic Multipoint Virtual Private Network Solution. The comparative analysis shows that EIGRP protocol is the best in terms of initial convergence delay, throughput, and queuing delay. BGP shows its efficiency compared to OSPF. The authors in [25] present compare the performance of all the distance vector and link state routing protocols with both IPv4 and IPv6 with default parameters. The results demonstrate that EIGRP has the best performance routing protocol under Distance Vector category of Routing Protocols, while OSPF is better than ISIS routing protocol under Link State Routing Category. P. Asher [26], discusses the routing process and looks at a generic classification of routing protocols. He also summarizes RIP, OSPF, IS-IS, IGRP, EIGRP and BGP protocols, and comparing their individual functioning. All the previous work they did not mention or take in considers 
the link path failure or a router is shutdown when they study or analysis the performance of routing protocols. This is the main objectives of our paper.

\section{Simulation Results and Discussion}

The aim of this work is to evaluate and compare the performance of dynamic routing protocols that include distance vector (RIP, EIGRP) and link state (OSPF) routing protocols. The comparison been done between three parameters, delay, Time-To-Live (TTL) and destination unreachable. The main difference between the three protocols is the metrics that each protocol uses for determining the best routes in the network. Looking at choosing between EIGRP and OSPF and to check which one more stability, best option, faster is for update the routing tables and selecting the best path, and which routing protocol is faster convergence than other, in case there are breakdowns in some routers. To achieve this, Packet Tracer simulation program was used to build the network topology as shown in Figure 1. The network topology connects a group of routers and configuration it's with three different types of routing protocols: RIP, EIGRP, and OSPF. The performance for each type of these protocols is measured and compared with different cases.

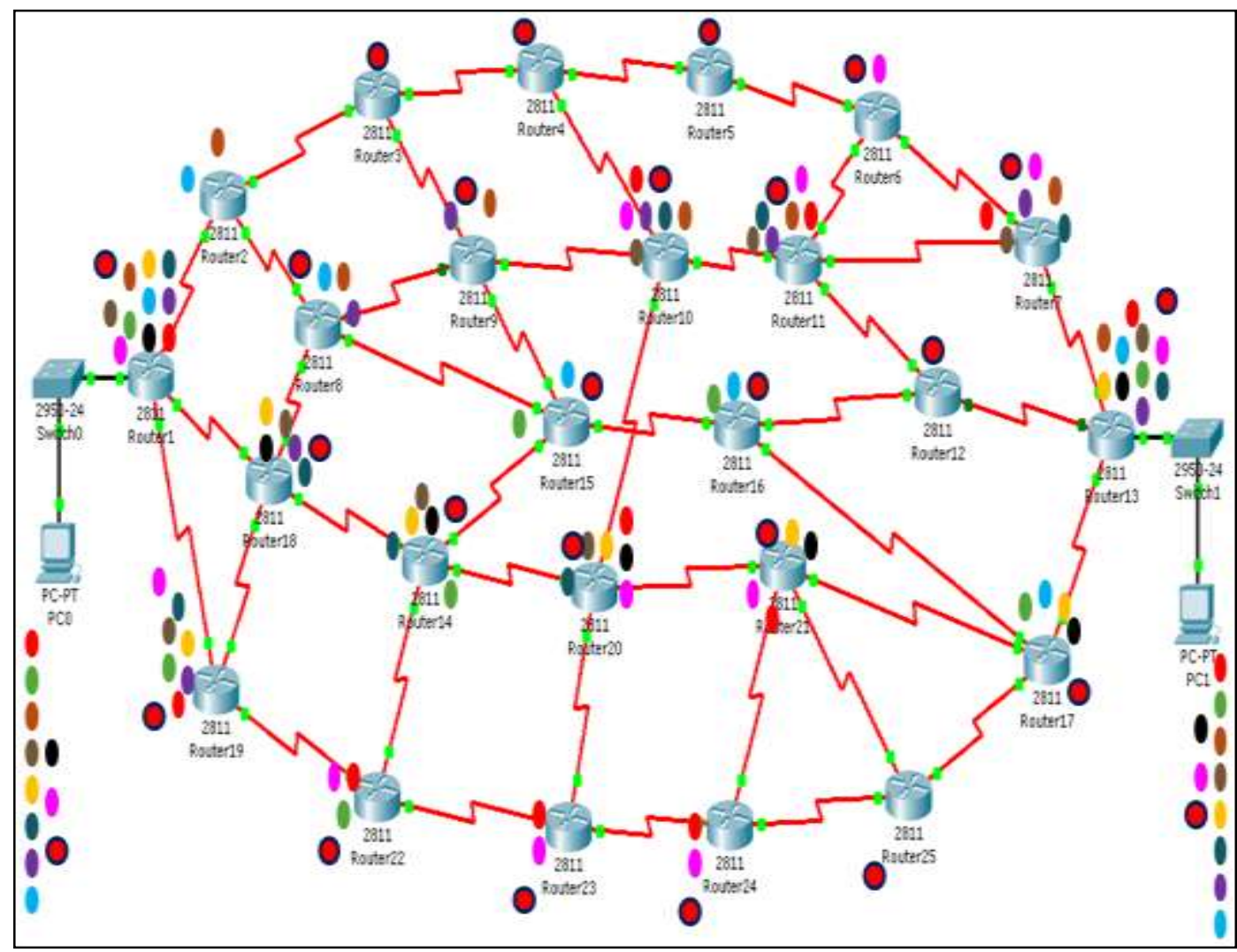

Figure 1. Network Topology Scenario with 25 Routers using RIP, EIGRP and OSPF Protocols

The design contains 25 routers as shown in Figure 1. Configuration these routers using RIP, EIGRP, and OSPF protocols and doing "ping" from $\mathrm{PC}_{0}$ to $\mathrm{PC}_{1}$ then record the results (i.e., TTL, delay, destination unreachable) for different cases, based on the respond and attitude for each protocol of the three protocols. Figure 1 shows the different routes, by applying the worst case on the three protocols (RIP, EIGRP, and OSPF) from $\mathrm{PC}_{0}$ to $\mathrm{PC}_{1}$, through different colors, and each color represent different path, while the red circle with black outer ring, it represents he worst case. 
The results present into two tables as shown in Table 1 and Table 2. The Tables present the results into two cases. Table 1 shows the general result for the experiment while Table 2 shows the worst case of the experiment, which it able to show how that every protocol performing in the hardest situations that it may face the routers when a big issue been happened such like a disaster like earthquake or flood or electricity fail. The comparison been done between three parameters, delay, Time-To-Live (TTL) and destination unreachable (request time out (RTO)).

Simulation results demonstrate that EIGRP routing protocol is fast convergence (lower delay) than RIP and OSPF (in some cases as shown in Table 1). The reason for that is, EIGRP faster to do update routing table (i.e., Triggered updates) and select the best new path. In case triggered updates, routing updates are sent only when there is a change in the topology. Therefore, we can describe the EIGRP protocol fast convergence than RIP protocol (Periodic Updates) as shown in Table 1 (Delay results) and as shown in Figure 2 that demonstrates the delay comparison between the RIP, EIGRP and OSPF.

Figure 3 shows the destination unreachable and request time out comparison for RIP, EIGRP and OSPF. The figure demonstrates the OSPF has lower destination unreachable and request time out and in some cases there are no destination unreachable and request time out, while the RIP, EIGRP have. However, the results in Table 2 show that the OSPF is faster for doing update (less delay) in the worst case (i.e., 9 routers breakdowns). In this case, the packets that send from $\mathrm{PC}_{0}$ reach to $\mathrm{PC}_{1}$ during delay $558 \mathrm{msec}$ and $104 \mathrm{TTL}$ with 2 unreachable, 1 request time out. While, in case RIP and EIGRP protocols, $\mathrm{PC}_{1}$ did not received the packets that sent from $\mathrm{PC}_{0}$.

In addition, the results from Tables 1 and 2 demonstrate the number of unreachable and request time out (RTO) in case OSPF is lower than in RIP and EIGRP protocols. So, based in these results, OSPF is more reliability than RIP and EIGRP. Although, OSPF is triggered updates like EIGRP, but the reason is that, the OSPF protocol save all the routes of the network in a big database. In case any changes occur in the network topology, the OSPF does not need to do a new update or to search about a new path to reach the destination.

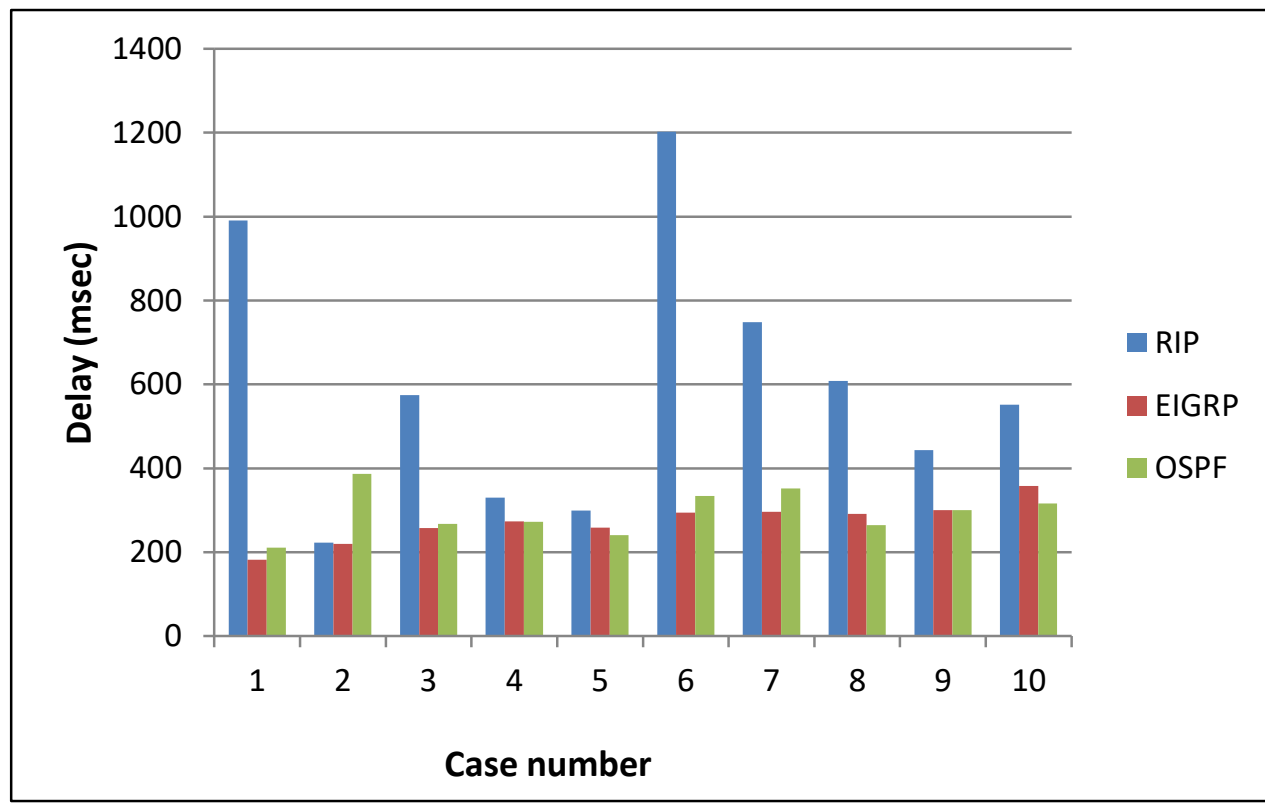

Figure 2. Delay Comparison for RIP, EIGRP, and OSPF in Case 25 Routers 


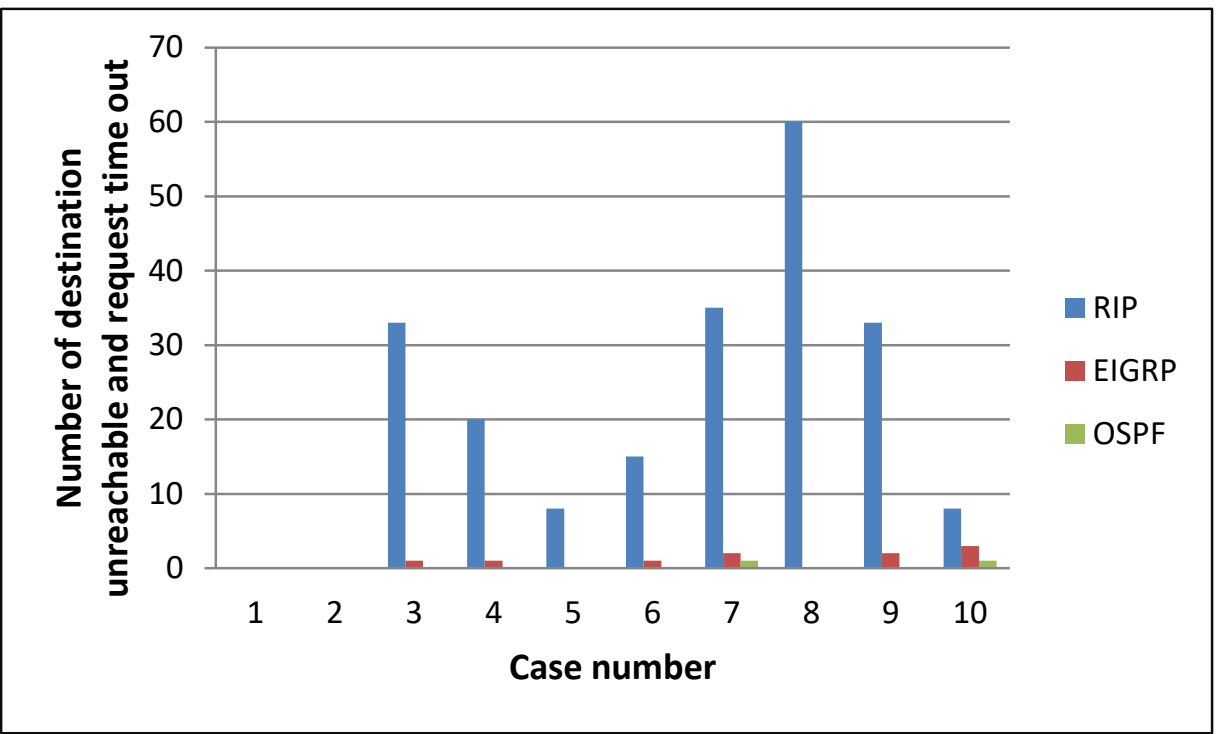

Figure 3. Comparison Destination Unreachable and Request Time out for RIP, EIGRP, and OSPF in Case 25 Routers

Table 1. Protocols General Case Results for 25 Routers

\begin{tabular}{|c|c|c|c|c|c|c|c|c|c|}
\hline \multirow{2}{*}{\multicolumn{2}{|c|}{$\begin{array}{l}\text { Path } \\
\text { color }\end{array}$}} & \multirow{2}{*}{$\begin{array}{c}\text { Router } \\
\text { No. }\end{array}$} & \multirow{2}{*}{$\begin{array}{c}\text { Shutdown } \\
\text { Port }\end{array}$} & \multicolumn{3}{|c|}{ Delay (msec) } & \multicolumn{3}{|c|}{ Unreachable } \\
\hline & & & & RIP & $\begin{array}{c}\text { EIGR } \\
P\end{array}$ & OSPF & RIP & $\begin{array}{c}\text { EIGR } \\
P\end{array}$ & OSPF \\
\hline 1 & O & - & - & 991 & 182 & 211 & --- & --- & --- \\
\hline 2 & C & 13 & $0,1,0$ & 223 & 220 & 387 & --- & --- & --- \\
\hline 3 & C & 13 & $\begin{array}{c}0,0,1 \& \\
0,1,0\end{array}$ & 574 & 258 & 267 & 33 & 1RTO & --- \\
\hline 4 & C & 1 & $\begin{array}{c}0,0,0 \& \\
0,1,0\end{array}$ & 330 & 273 & 272 & 20 & 1 & --- \\
\hline 5 & C & $1 \& 13$ & $\begin{array}{c}0,0,0 \& \\
0,1,0 / 0,1,0\end{array}$ & 299 & 259 & 241 & 8 & --- & --- \\
\hline 6 & 0 & $1 \& 13$ & $\begin{array}{c}0,0,0 \& \\
0,1,0 / 0,1,0 \\
\& 0,0,1\end{array}$ & $\begin{array}{c}120 \\
2\end{array}$ & 294 & 334 & $\begin{aligned} & 13 \mathrm{un} \\
+ & 2 \mathrm{RTO}\end{aligned}$ & 1RTO & --- \\
\hline 7 & 0 & $1 \& 13$ & $\begin{array}{c}0,0,0 \& \\
0,1,0 / 0,1,0 \\
\& 0,0,1\end{array}$ & 748 & 296 & 352 & 35 & 2 & $1 \mathrm{RTO}$ \\
\hline 8 & 0 & $\begin{array}{c}1,13,20 \\
14\end{array}$ & $\begin{array}{c}0,0,0 \& \\
0,1,0 / 0,1,0 \\
\& 0,0,1 / \\
0,0,0 / 0,1,1\end{array}$ & 608 & 291 & 264 & $\begin{array}{l}\text { 50un+ } \\
10 \mathrm{RTO}\end{array}$ & --- & --- \\
\hline 9 & & $\begin{array}{c}1,13,20 \\
14,18\end{array}$ & $\begin{array}{c}0,0,0 \& \\
0,1,0 / 0,1,0 \\
\& 0,0,1 / \\
0,0,0 / 0,1,1 / 0 \\
, 0,0\end{array}$ & 443 & 300 & 300 & $\begin{array}{c}23 \text { un+ } \\
10 \text { RTO }\end{array}$ & 2 & --- \\
\hline 10 & 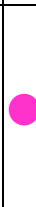 & $\begin{array}{c}1,13,20 \\
14,18,1 \\
7\end{array}$ & $\begin{array}{c}0,0,0 \& \\
0,1,0 / 0,1,0 \\
\& 0,0,1 / \\
0,0,0 / 0,1,1 / 0 \\
, 0,0 / 0,1,0\end{array}$ & 552 & 358 & 316 & 8 & 3 & $1 \mathrm{RTO}$ \\
\hline
\end{tabular}


Table 2. Worst Case Results Performance in Case 25 Routers

\begin{tabular}{|c|c|c|c|c|c|c|c|c|c|c|c|}
\hline \multirow{2}{*}{$\begin{array}{l}\text { Path } \\
\text { color }\end{array}$} & \multirow{2}{*}{$\begin{array}{c}\text { Router } \\
\text { No. }\end{array}$} & \multirow{2}{*}{$\begin{array}{c}\text { Shutdown } \\
\text { Port }\end{array}$} & \multicolumn{3}{|c|}{ Delay $(\mathrm{msec})$} & \multicolumn{3}{|c|}{ TLL } & \multicolumn{3}{|c|}{ Unreachable } \\
\hline & & & $\begin{array}{c}\text { RI } \\
P\end{array}$ & $\begin{array}{l}\text { EIG } \\
\text { RP }\end{array}$ & $\begin{array}{c}\text { OSP } \\
\text { F }\end{array}$ & $\begin{array}{c}\text { RI } \\
\mathrm{P}\end{array}$ & $\begin{array}{l}\text { EIG } \\
\text { RP }\end{array}$ & $\begin{array}{c}\text { OSP } \\
\text { F }\end{array}$ & $\begin{array}{l}\text { RI } \\
\mathrm{P}\end{array}$ & $\begin{array}{l}\text { EIG } \\
\text { RP }\end{array}$ & OSPF \\
\hline & 1 & $\begin{array}{c}0,0,0 \& \\
0,1,0 \\
\end{array}$ & \multirow{14}{*}{---} & \multirow{14}{*}{--- } & \multirow{14}{*}{558} & \multirow{14}{*}{---} & \multirow{14}{*}{--- } & \multirow{14}{*}{104} & \multirow{14}{*}{---} & \multirow{14}{*}{---} & \multirow{14}{*}{$\begin{array}{c}2 \text { un }+1 \\
\text { RTO }\end{array}$} \\
\hline & 13 & $\begin{array}{c}0,1,0 \& \\
0,0,1\end{array}$ & & & & & & & & & \\
\hline & 20 & $0,0,0$ & & & & & & & & & \\
\hline & 14 & $0,1,1$ & & & & & & & & & \\
\hline & 18 & $0,0,0$ & & & & & & & & & \\
\hline & 17 & $0,1,0$ & & & & & & & & & \\
\hline & 21 & $\begin{array}{c}0,1,0 \& \\
0,0,1\end{array}$ & & & & & & & & & \\
\hline & 10 & $0,1,1$ & & & & & & & & & \\
\hline & 16 & $0,0,0$ & & & & & & & & & \\
\hline & 15 & $0,1,0$ & & & & & & & & & \\
\hline & 2 & $0,1,0$ & & & & & & & & & \\
\hline & 4 & $0,1,0$ & & & & & & & & & \\
\hline & 6 & $0,1,0$ & & & & & & & & & \\
\hline & 9 & $\begin{array}{c}0,0,0 \& \\
0,1,1\end{array}$ & & & & & & & & & \\
\hline
\end{tabular}

Figure 4 shows the second scenario for network topology connects 12 routers, these routers configure with three different types of routing protocols: RIP, EIGRP, and OSPF. The aim of this scenario is to study the performance for the routing protocols in case a few number of routers in the network. Figure 5 shows the delay comparison between the RIP, EIGRP and OSPF. The OSPF has low delay value compare with the RIP and EIGRP

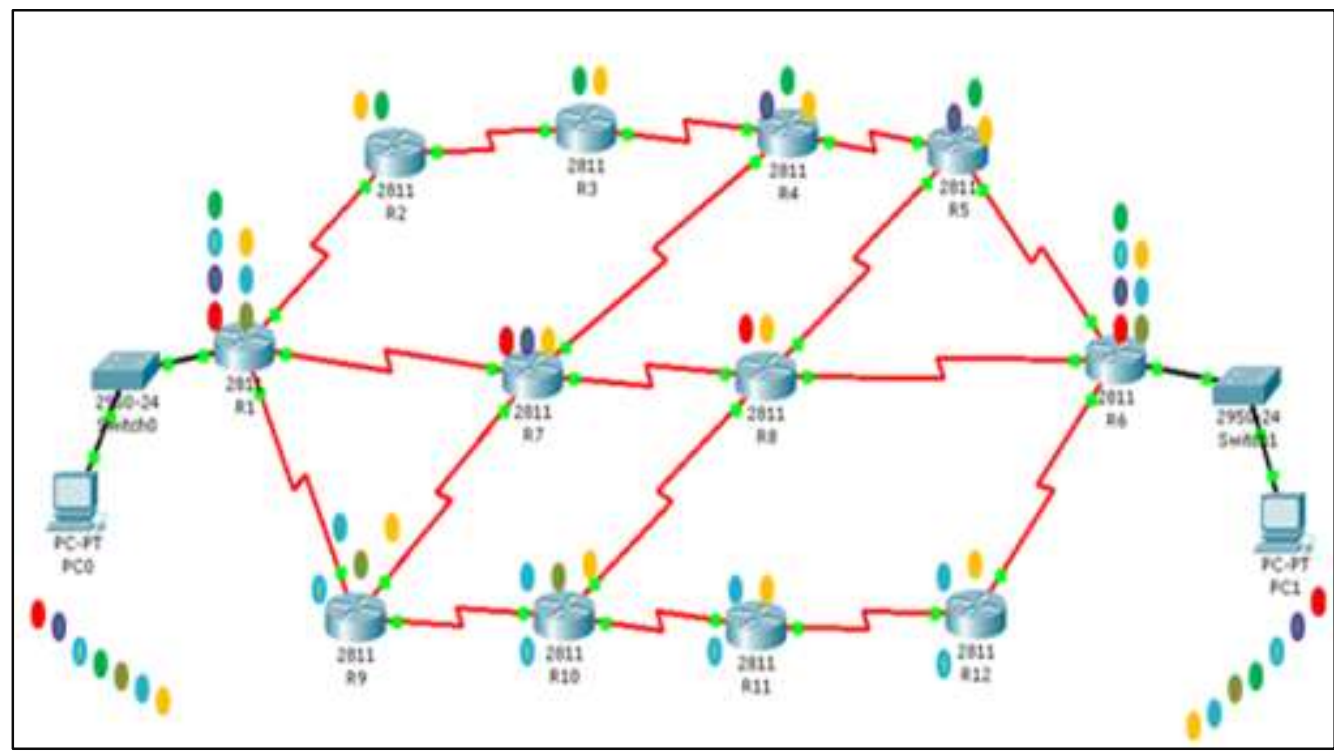

Figure 4. Network Topology Scenario with 12 Routers using RIP, EIGRP and OSPF Protocols 


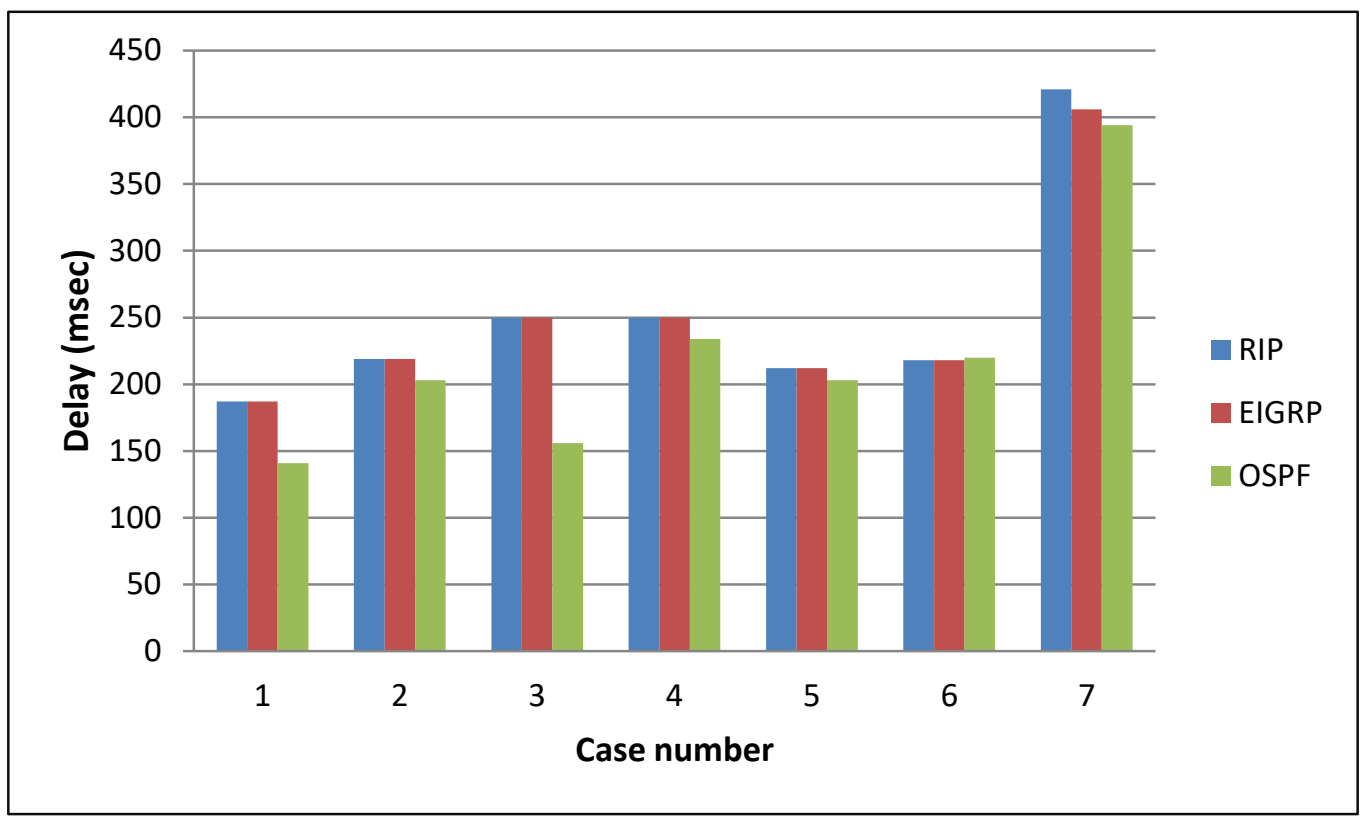

Figure 5. Delay Comparison for RIP, EIGRP, and OSPF in Case 12 Routers

Figure 6 shows the comparison of destination unreachable and request time out for RIP, EIGRP and OSPF. The figure shows that the OSPF has lower destination unreachable and request time out and in some cases there are no destination unreachable and request time out, while the RIP, EIGRP have.

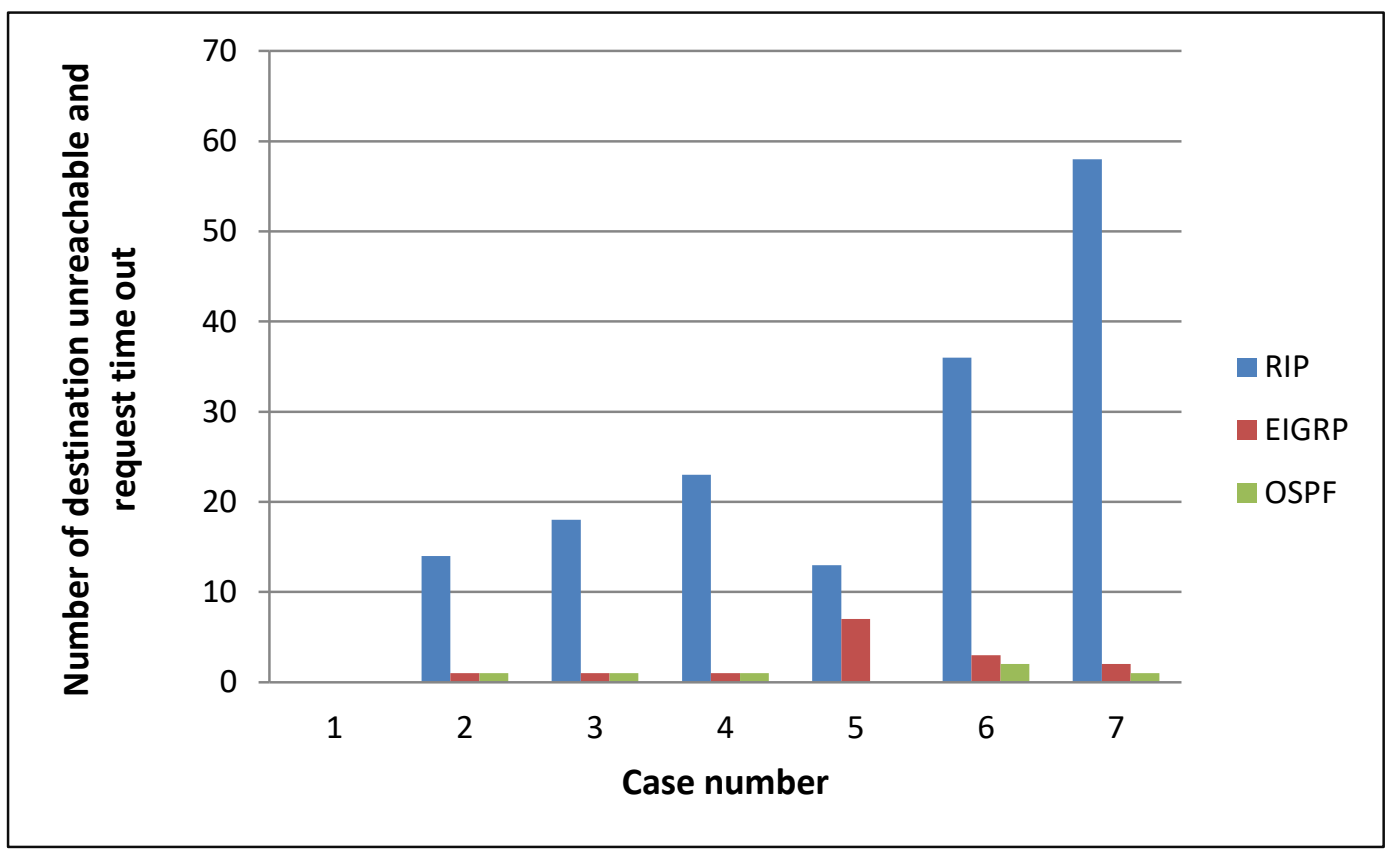

Figure 6. Comparison Destination Unreachable and Request Time out for RIP, EIGRP, and OSPF in Case 12 Routers

Table 3 shows the general result and the comparison for the delay, and destination unreachable (request time out (RTO)) for the second scenario in case 12 routers. The feature differences and comparison between the supported dynamic routing protocols are summarized in the Table 4. 
Table 3. Protocols General Case Results for 12 Routers

\begin{tabular}{|c|c|c|c|c|c|c|c|c|c|}
\hline \multirow{2}{*}{\multicolumn{2}{|c|}{ Path color }} & \multirow{2}{*}{$\begin{array}{c}\text { Router } \\
\text { No. }\end{array}$} & \multirow{2}{*}{$\begin{array}{c}\text { Shutdown } \\
\text { Port }\end{array}$} & \multicolumn{3}{|c|}{ Delay (msec) } & \multicolumn{3}{|c|}{ Unreachable } \\
\hline & & & & RIP & EIG & OSPE & PID & EIGR & OCPF \\
\hline 1 & 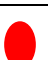 & ----- & ---- & 187 & 187 & 141 & ------ & ------ & ------ \\
\hline 2 & C & 6 & $0,1,0$ & 219 & 219 & 203 & 14 & 1 & $\begin{array}{c}1 \\
\text { RTO }\end{array}$ \\
\hline 3 & & 6 & $\begin{array}{l}0,0,0 \\
0,1,0\end{array}$ & 250 & 250 & 156 & 18 & $\begin{array}{c}1 \\
\text { RTO }\end{array}$ & $\begin{array}{c}1 \\
\text { RTO }\end{array}$ \\
\hline 4 & & 1 & $\begin{array}{l}0,0,0 \\
0,1,1\end{array}$ & 250 & 250 & 234 & $\begin{array}{c}17+6 \\
\text { RTO }\end{array}$ & $\begin{array}{c}1 \\
\text { RTO }\end{array}$ & $\begin{array}{c}1 \\
\text { RTO }\end{array}$ \\
\hline 5 & & 1 & $\begin{array}{l}0,0,0 \\
0,1,0\end{array}$ & 212 & 212 & 203 & $\begin{array}{l}6+7 \\
\text { RTO }\end{array}$ & 7 & --- \\
\hline 6 & & $\begin{array}{l}7 \\
8 \\
1\end{array}$ & $\begin{array}{l}0,0,0 \\
0,0,0 \\
0,0,0 \\
0,1,0\end{array}$ & 218 & 218 & 220 & 36 & $\begin{array}{c}2+1 \mathrm{R} \\
\mathrm{TO}\end{array}$ & $\begin{array}{c}2 \\
\text { RTO }\end{array}$ \\
\hline 7 & 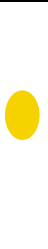 & $\begin{array}{l}1 \\
4 \\
6 \\
8\end{array}$ & $\begin{array}{l}0,0,0 \\
0,1,1 \\
0,1,0 \\
0,0,0 \\
0,1,0 \\
0,0,0\end{array}$ & 421 & 406 & 394 & 58 & $\begin{array}{c}2 \\
\text { RTO }\end{array}$ & $\begin{array}{c}1 \\
\text { RTO }\end{array}$ \\
\hline
\end{tabular}

Table 4. Protocols Comparison

\begin{tabular}{|c|c|c|c|}
\hline Attribute & RIP & EIGRP & OSPF \\
\hline Network Size & $\begin{array}{c}\text { Suitable for small to } \\
\text { medium networks due to } \\
\text { the max. hops metric is } \\
15\end{array}$ & $\begin{array}{c}\text { Suitable for small and } \\
\text { large networks. }\end{array}$ & $\begin{array}{c}\text { Suitable for small and } \\
\text { large networks. }\end{array}$ \\
\hline $\begin{array}{c}\text { Maximum Hop } \\
\text { Count }\end{array}$ & 15 & 224 & None \\
\hline $\begin{array}{c}\text { Need of Device } \\
\text { Resources }\end{array}$ & $\begin{array}{c}\text { Much less memory and } \\
\text { CPU intensive than } \\
\text { OSPF }\end{array}$ & $\begin{array}{c}\text { Lower CPU and } \\
\text { memory requirements }\end{array}$ & $\begin{array}{c}\text { Requires higher } \\
\text { processing and memory } \\
\text { than RIP and EIGRP }\end{array}$ \\
\hline Convergence & Slow & $\begin{array}{c}\text { Converges quickly than } \\
\text { EIGRP }\end{array}$ \\
\hline $\begin{array}{c}\text { Need of Network } \\
\text { Resources }\end{array}$ & $\begin{array}{c}\text { Bandwidth consuming; } \\
\text { due to periodic complete } \\
\text { updating of routing table }\end{array}$ & $\begin{array}{c}\text { Less than OSPF } \\
\text { Metric }\end{array}$ & $\begin{array}{c}\text { Less than RIP; Only } \\
\text { small Updates are sent. }\end{array}$ \\
\hline Configure & Easy to configure & $\begin{array}{c}\text { Bandwidth, line delay, } \\
\text { load, and reliability }\end{array}$ & Bandwidth \\
\hline Protocol Type & Distance Vector & $\begin{array}{c}\text { Enhanced Distance } \\
\text { Vector (hybrid) }\end{array}$ & Complicated to configure \\
\hline Link Failures & $\begin{array}{c}\text { Slow to adjust the link } \\
\text { failure }\end{array}$ & $\begin{array}{c}\text { Quickly adjusts to link } \\
\text { failures }\end{array}$ & $\begin{array}{c}\text { Rapidly adjusts to link } \\
\text { failures than EIGRP }\end{array}$ \\
\hline Routing Algorithm & Bellman-Ford & DUAL & Dijkstra \\
\hline
\end{tabular}




\section{Conclusion}

A performance comparison between dynamic routing protocols RIP, EIGRP, and OSPF is presented in this paper. Performance of a dynamic routing protocol can change with different network topologies. The paper shows how the number of routers is effecting on the performance of the network such as delay and converges. The results demonstrate that the OSPF is faster convergence and more reliability than RIP and EIGRP. It is better to choose the OSPF instead of EIGRP in the enterprise network that has more than 15 routers. In case any change occurs in the network topology, the OSPF does not need to do a new update or to search about a new path to reach the destination.

\section{References}

[1] K. Zajda, "Evaluation of possible applications of dynamic routing protocols for load balancing in computer networks", Theoretical and Applied Informatics, vol. 22, no. 2, (2010), pp. 141-151.

[2] S. M. Sheikh, R. Wolhuter and G. J. v. Rooyen, "A comparative analysis of MANET routing protocols for low cost rural telemetry Wireless Mesh Networks", IEEE International Conference on Emerging Trends in Networks and Computer Communications (ETNCC), (2015), pp. 32-37.

[3] S. G. Thorenoor, "Dynamic routing protocol implementation decision between EIGRP, OSPF and RIP based on technical background using OPNET Modeler", Second International Conference on Computer and Network Technology (ICCNT), (2010), pp. 191-195.

[4] M. A. Yehia, M. S. Aziz and H. A. Elsayed, "Analysis of IGP Routing Protocols for Real Time Applications: A Comparative Study", International Journal of Computer Applications, vol. 26, no. 3, (2011), pp. 11-17.

[5] E. M. Royer and C.-K. Toh, "A review of current routing protocols for ad hoc mobile wireless networks", IEEE Personal Communications, vol. 6, (1999), pp. 46-55.

[6] M. R. Pearlman, Z. J. Haas, P. Sholander and S. S. Tabrizi, "On the impact of alternate path routing for load balancing in mobile ad hoc networks", First Annual Workshop on Mobile Ad Hoc Networking and Computing MobiHOC, (2000), pp. 3-10.

[7] O. Sharon, "Dissemination of routing information in broadcast networks: OSPF versus IS-IS", IEEE Network, vol. 15, (2001), pp. 56-65.

[8] P. Jacquet, P. Muhlethaler, T. Clausen, A. Laouiti, A. Qayyum and L. Viennot, "Optimized link state routing protocol for ad hoc networks", IEEE International Conference Multi Topic Technology for the 21st Century, (2001), pp. 62-68.

[9] S. Sirika and S. Mahajan, "Survey on Dynamic Routing Protocols", International Journal of Engineering Research \& Technology (IJERT), vol. 5, no. 1, (2016), pp. 10-14.

[10] A. Verma and N. Bhardwaj, "A Review on Routing Information Protocol (RIP) and Open Shortest Path First (OSPF) Routing Protocol", International Journal of Future Generation Communication and Networking, vol. 9, no. 4, (2016), pp. 161-170.

[11] S. K. Narisetty and S. K. Balsu, "Performance Comparison of EIGRP and ISIS/RIP Protocols", International Journal of Research and Reviews in Ad Hoc Networks (IJRRAN), vol. 3, (2011), pp. 6366.

[12] M. N. Islam and M. A. U. Ashique, "Simulation Based EIGRP over OSPF Performance Analysis", School of Computing, Electrical Engineering Emphasis on Telecommunications, Blekinge Institute of Technology, School of Computing, Electrical Engineering Emphasis on Telecommunications, (2010).

[13] D. Xu, "Final Project OSPF, EIGRP and RIP Performance Analysis Based on OPNET", ENSC835: Communication Networks, (2011), pp. 1-11.

[14] F. A. Hamza and A. M. Mohamed, "Performance Comparison of Two Dynamic Routing Protocols: RIP and OSPF", Journal of Emerging Trends in Computing and Information Sciences, vol. 2, no. 10, (2011), pp. 509-513.

[15] J. P. Adhikari, "Performance Analysis of protocols RIP \& EIGRP", International Journal of Innovative Technology and Exploring Engineering (IJITEE) ISSN, vol. 2, no. 1, (2013), pp. 2278-3075.

[16] R. Vohra Sonam and R. S. Sawhney, "Dynamic Routing Protocols Analysis based on Dissimilar Number of Packets", The SIJ Transactions on Computer Networks \& Communication Engineering (CNCE), vol. 2, no. 4, (2014), pp. 50-55.

[17] N. Nazumudeen and C. Mahendran, "Performance Analysis of Dynamic Routing Protocols Using Packet Tracer", International Journal of Innovative Research in Science, Engineering and Technology, vol. 3, no. 1, (2014), pp. 570-574.

[18] J. Kumar, A. Kaur Samiksha and H. singh, "Performance Analysis of RIPv2 protocol in Wired Network Using Cisco Packet Tracer", Int. J. Computer Technology and Applications, vol. 6, no. 1, (2015), pp. 16. 
[19] D. V. Prasad, S. Jaganathan and G. P. Saikalyan, "Study and Analysis of Dynamic Routing Protocols in real time for Optimal Resource Utilization", International Journal of Communications, vol. 1, no. 1, (2016), pp. 21-29.

[20] I. Dogan, and E. Bostanci, "Analysing Performances of Dynamic Routing Protocols on Various Network Topologies", Journal of Advances in Computer Networks, vol. 4, no. 2, (2016), pp. 125-130.

[21] K. Grover, P. Bansal and R. Shetty, "Comparison of Routing Protocols RIP, OSPF and EIGRP", International Journal of Application or Innovation in Engineering and Management, vol. 6, no. 2, (2017), pp. 8-19.

[22] A. C, "Analysis of RIPv2, OSPF, EIGRP Configuration on router Using CISCO Packet tracer", International Journal of Engineering Science and Innovative Technology (IJESIT), vol. 4, no. 2, (2015), pp. 215-222.

[23] S. Sirika and S. Mahajine, "Performance Evaluation of Dynamic Routing Protocols for Real time application", International Journal of Engineering Trends and Technology (IJETT), vol. 32, no. 7, (2016), pp. 328-337.

[24] A. Bahnasse and N. E. Kamoun, "Study and Analysis of a Dynamic Routing Protocols' Scalability over a Dynamic Multi-point Virtual Private Network", International Journal of Computer Applications, vol. 123, no. 2, (2015), pp. 26-31.

[25] B. Rathi and E. F. Singh, "Performance Analysis of Distance Vector and Link State Routing Protocols", International Journal of Computer Science Trends and Technology (IJCST), vol. 3, no. 4, (2015), pp. 2332.

[26] P. Asher, "Comprehensive Analysis of Dynamic Routing Protocols in Computer Networks", International Journal of Computer Science and Information Technologies, vol. 6, no. 5, (2015), pp. 4450-4455.

\section{Authors}

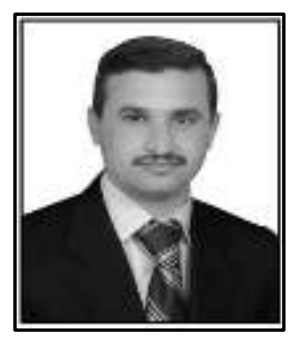

Salah Abdulghani Alabady, received the Ph.D. degree in computer engineering/wireless networks from the School of Electrical and Electronic Engineering, Universiti Sains Malaysia, Pulau Pinang, Malaysia, in 2014. From 1999 to 2010, he was a Lecturer with the Computer Engineering Department, University of Mosul, Iraq, where he is currently a Senior Lecturer. From 2011 to 2014, he was a Research Assistant in wireless networks with the School of Electrical and Electronic Engineering, Universiti Sains Malaysia. His research interests include wireless channel coding, joint channel-network coding, error correction codes, and cross layer of wireless sensor networks.

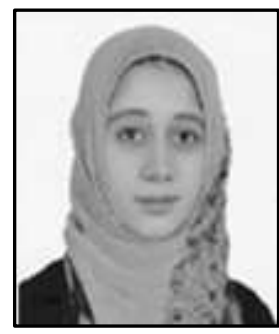

Sara Hazim, received her BSc in Computer Engineering in 2010 from the University of Mosul, Iraq. Currently she working in civil Engineering Department as a computer engineer. Her research interests include analyzing and managing Ethernt and wireless networks, analyzing the performnace of different routing protocols.

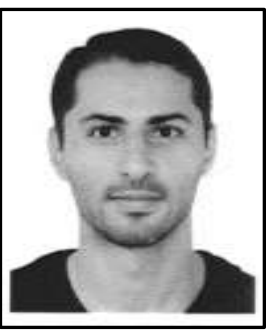

Abdullah Amer Mohammed Salih, is currently a Ph.D. candidate at Universiti Sains Malaysia (USM), the Department of Electrical, and Electronics Engineering. He received a B.S. in Software Engineering from Al-Mansour University College, Baghdad, Iraq, in 2008, and a Master in Electrical Computer Engineering from Universiti Sains Malaysia (USM), in 2014. His current research interests in image processing and computer vision. As of now, he is a member of Imaging and Intelligent System Research Team (ISRT) research group. 
International Journal of Grid and Distributed Computing

Vol. 11, No. 7 (2018) 